\title{
'Candidatus Rickettsia asemboensis' and Wolbachia spp. in Ctenocephalides felis and Pulex irritans fleas removed from dogs in Ecuador
}

\author{
José A Oteo ${ }^{1 *}$, Aránzazu Portillo ${ }^{1}$, Francisco Portero ${ }^{2}$, Jorge Zavala-Castro ${ }^{3}$, José M Venzal ${ }^{4}$ and Marcelo B Labruna $^{5}$
}

\begin{abstract}
Background: Flea-borne infections are distributed worldwide. Up to date there are no reports about microorganisms associated to fleas in Ecuador.

Methods: Seventy-one Pulex irritans and 8 Ctenocephalides felis fleas were removed from dogs in two Ecuadorian areas (Pastaza and Chimborazo Provinces) in December 2012. DNA extracts were tested by polymerase chain reaction (PCR) assays targeting universal $16 \mathrm{~S}$ rRNA, as well as screened for the presence of Rickettsia spp. (gltA, htrA, ompB, sca4 and ompA genes) and Bartonella spp. (rpoB, gltA and ITS genes).

Results: Our results showed the presence of 'Candidatus Rickettsia asemboensis' (highly similar to $R$. felis) in C. felis and Wolbachia spp. endosimbionts in P. irritans collected from animals in Ecuador. No fleas were found to be positive for any Bartonella species or Yersinia pestis.
\end{abstract}

Conclusions: Clinicians should be aware of the potential risk of this new Candidatus Rickettsia sp. and keep in mind other flea-borne infections since these flea species frequently bite humans.

Keywords: Fleas, Pulex irritans, Ctenocephalides felis, Ecuador, 'Candidatus Rickettsia asemboensis', Wolbachia spp., Bartonella spp., Yersinia pestis, Plague

\section{Background}

Flea-borne diseases are worldwide-distributed emerging and re-emerging infections. Among them, plague, which is caused by Yersinia pestis, is the most severe human infection transmitted by fleas [1]. In South America, permanent plague foci exist among native rodent and flea populations in Bolivia, Brazil, Ecuador and Peru [2]. Rats have been the responsible hosts and from them, the disease has spread to other rodents. Ecuador is considered a plague 'hot-spot' since its introduction in 1908, and has experienced important outbreaks. Chimborazo Province has historically been a highly endemic area and the last fatal Ecuadorian cases of plague were reported there in 2004 [3,4].

In addition, fleas are vectors of murine typhus (caused by Rickettsia typhi), flea-borne spotted fever (caused by

\footnotetext{
* Correspondence: jaoteo@riojasalud.es

'Departamento de Enfermedades Infecciosas, Hospital San Pedro-Centro de Investigación Biomédica de La Rioja (CIBIR), C/ Piqueras 98, 26006 Logroño (La Rioja), Spain

Full list of author information is available at the end of the article
}

Rickettsia felis) and harbour Bartonella spp. [1,5-7]. Recent evidence of murine typhus in Ecuador is lacking, but the disease may be endemic in localities where commensal rodents (Rattus spp.) are abundant. To the best of our knowledge, data about distribution of $R$. felis in this country are unknown and there are no reports describing Bartonella spp. in fleas from Ecuador. For these reasons, our interest was focused on the study of fleaborne agents in two Ecuadorian areas (one of them where the last plague outbreak occurred) using molecular biological methods [polymerase chain reaction (PCR) and DNA sequencing].

\section{Methods}

In December 2012, a total of 79 fleas were removed from dogs by members of Red Iberoamericana para la Investigación y Control de las Enfermedades Rickettsiales, Programa Iberoamericano de Ciencia y Tecnologías para el Desarrollo (RIICER, CYTED; no. 210RT0403). Fifty-two specimens (44 Pulex irritans and 8 Ctenocephalides felis) 
were collected in the Estación Experimental Fátima (ESPOCH), Cantón Puyo, in Pastaza Province (01 $24^{\circ} 34.6^{\prime \prime}$; $77^{\circ} 59^{\prime} 57.5^{\prime \prime} \mathrm{W}$ ), and 27 specimens (all P. irritans) were collected in Cantón Guamote, in Chimborazo Province $\left(02^{\circ} 00^{\prime} 25.0^{\prime \prime} \mathrm{S} ; 7^{\circ} 47^{\prime} 09.3^{\prime \prime} \mathrm{W}\right)$. The study areas had altitudes of $1,034 \mathrm{~m}$ and 3,657 m, respectively. After identification at the species level, samples were kept in $70 \%$ ethanol at room temperature before being tested. DNA of each arthropod was extracted by lysis with $0.7 \mathrm{M}$ ammonium hydroxide and tested by PCR with the universal primers $\mathrm{fD} 1$ and $\mathrm{rp} 2$ [8]. This primer pair amplifies the main part of the 16S rRNA gene and has been used for the identification of $Y$. pestis as the causative agent of plague in India [9]. Samples were also screened for the presence of Rickettsia spp. with PCR assays targeting rickettsial citrate synthase (glt $A$ ) and $17 \mathrm{kDa}$ antigen $(h \operatorname{tr} A)$ genes [10,11]. In accordance with the taxonomic scheme [12], additional rickettsial genes (ompB, sca4 and ompA) were tested to properly identify Rickettsia-positive specimens [13-17]. Moreover, Bartonella spp. was tested using RNA polymerase $\beta$-subunit-encoding gene $(r p o B)$, glt $A$ and intergenic spacer region gene (ITS) PCR primers, which amplify fragments of Bartonella genes [18-20].

Each PCR included positive controls consisting of Bartonella henselae DNA extracted from a cat flea (C. felis) from La Rioja - Spain, or Rickettsia slovaca strain S14ab DNA (obtained from Vero cells inoculated in our facility with a Dermacentor marginatus tick from La Rioja - Spain, and known to be infected with $R$. slovaca). Negative controls (DNA-free water) were included in all assays. Sequences generated by each pair of primers were then compared with those in GenBank using BLAST (www.ncbi.nlm.nih.gov/blast/Blast.cgi).

\section{Results and discussion}

PCR assays using universal eubacterial primers for $16 \mathrm{~S}$ rRNA gene yielded amplicons of different intensity for 69 out of 79 fleas (8/8 C. felis and 35/44 P. irritans from Pastaza and 26/27 P. irritans from Chimborazo). All C. felis $(\mathrm{n}=8)$ were also found to be infected with Rickettsia species using gltA and htrA as rickettsial PCR targets, whereas no evidence of Rickettsia spp. was found in $P$. irritans. Moreover, no sample was positive for Bartonella species as determined either by rpoB, gltA or ITS PCR assays. Positive and negative controls worked as expected in all cases.

Sequences of rickettsial 16S rRNA gene obtained from 7/8 C. felis (1303-1373 bp) showed the closest identity (99.6-99.9\%) with 'Candidatus Rickettsia asemboensis', a potentially new Rickettsia species according to the established criteria [12,21] (Table 1). In these samples, the percentage of identity with $16 \mathrm{~S}$ rRNA gene of a validly published Rickettsia species reached $99.4 \%$ for $R$. felis (accession no. NR074483). The 1387 bp-long sequence of $16 \mathrm{~S}$ rRNA gene obtained from the remaining C. felis had the highest identity (97.1\%) with a sequence from uncultured flea-associated bacterium [22], and showed 93.6\% identity with Snodgrasella alvi, betaproteobacteria classified in the family Neisseriaceae and previously isolated from the bee gut [23] (Table 1).

Sequencing of $g l t A$ fragments $(350 \mathrm{bp}$ ) identified $R$. felislike rickettsiaceae in C. felis (100\% identity with Rickettsia sp. genotype RF2125) [24] and showed 99.7\% identity (349/350 bp) with 'Candidatus R. asemboensis' (Table 1). The sequences of the $17-\mathrm{kDa}$ amplicons (394 bp) were homologous ( $100 \%$ identical) to each other and to ' $\mathrm{Ca}$. $\mathrm{R}$. asemboensis' as well as to other molecular isolates included in the $R$. felis-like genotype group (Rickettsia sp. SE313 detected in Echidnophaga gallinacea from Egypt and Rickettsia sp. cfland5 detected in C. felis from USA) (Table 1).

The sequences of $о m p B$ and sca4 amplicons (464 and $352 \mathrm{bp}$, respectively) were also $100 \%$ identical to ' $\mathrm{C} a$. R. asemboensis' (Table 1). Unfortunately, ompA PCR primers did not yield amplicons of the expected size, and inconclusive sequences were obtained for this target gene.

Percentages of identity with validated species $R$. felis (accession no. CP000053) were 98.6, 96.2, 97.9 and 96.6\% for gltA, htrA, ompB and sca4 genes, respectively.

In addition, 59 out of 61 sequences of 16S rRNA gene obtained from $61 \mathrm{P}$. irritans specimens provided evidence of the presence of probable endosymbionts similar to those found within other arthropods and belonging to the genus Wolbachia (Table 2). Unfortunately, in two cases (corresponding to two P. irritans samples from Chimborazo) it was not possible to get a good-quality sequence to identify the bacteria.

In our study 'Candidatus $\mathrm{R}$. asemboensis' has been found in fleas that bite humans (C. felis) removed from dogs in Ecuador. This potential new species was previously detected in Ctenocephalides canis from Kenya and whether it is a human pathogen remains unknown [21]. 'Ca. R. asemboensis' is highly similar to Rickettsia RF2125, a member of the $R$. felis-like genotype group that circulates in fleas from Uruguay [25]. Apart from epidemic typhus (caused by Rickettsia prowazekii and transmitted by lice), no data about human diseases associated with Rickettsia species have been published from Ecuador [26]. Nevertheless, in the Pastaza province (one of our sampling areas) cases of acute undifferentiated febrile illness compatible with rickettsioses have been reported [27].

Up to the present study, the presence of $R$. felis and/or Bartonella spp. has not been demonstrated in fleas from Ecuador. However, $R$. felis has been found in South American fleas from Brazil, Peru, Uruguay, Chile, Argentina and Colombia [11,25,28-31]. In addition, human 
Table 1 Results of nucleotide sequence analysis corresponding to PCR products amplified from the 8 Ctenocephalides felis specimens of this study

\begin{tabular}{|c|c|c|c|c|c|c|}
\hline Gene* & Flea gender ${ }^{1}$ & Location & $\begin{array}{l}\text { Length of } \\
\text { sequence (bp) }\end{array}$ & $\%$ identity & Bacteria with closest identity in the BLAST search & GenBank accession no. \\
\hline \multirow[t]{3}{*}{ 16S rRNA } & $1 / 2 \mathrm{M} ; 6 / 6 \mathrm{~F}$ & Pastaza & 1303-1373 & $99.6-99.9$ & 'Candidatus Rickettsia asemboensis' (Rickettsia F30) & JN315967 \\
\hline & $1 / 2 \mathrm{M} ; 0 / 6 \mathrm{~F}$ & Pastaza & 1387 & 97.1 & Uncultured flea-associated bacterium & EU137419 \\
\hline & & & & 93.6 & Snodgrasella alvi & JQ746645 \\
\hline \multirow[t]{2}{*}{ glt $A$} & $2 / 2 \mathrm{M} ; 6 / 6 \mathrm{~F}$ & Pastaza & 350 & 100 & Rickettsia felis-like (Rickettsia RF2125) & AF516333 \\
\hline & & & & 99.7 & 'Candidatus Rickettsia asemboensis' (Rickettsia F30) & JN315968 \\
\hline htrA & $2 / 2 \mathrm{M} ; 6 / 6 \mathrm{~F}$ & Pastaza & 394 & 100 & $\begin{array}{l}\text { 'Candidatus Rickettsia asemboensis' (Rickettsia F30)/ } \\
\text { Rickettsia felis-like (Rickettsia SE313/cf1and5) }\end{array}$ & $\begin{array}{l}\text { JN315969/DQ166937/ } \\
\text { AY953286 }\end{array}$ \\
\hline$o m p B$ & $2 / 2 \mathrm{M} ; 6 / 6 \mathrm{~F}$ & Pastaza & 464 & 100 & 'Candidatus Rickettsia asemboensis' (Rickettsia F30) & JN315972 \\
\hline sca4 & $2 / 2 M ; 6 / 6 \mathrm{~F}$ & Pastaza & 352 & 100 & 'Candidatus Rickettsia asemboensis' (Rickettsia F30) & JN315970 \\
\hline
\end{tabular}

*Inconclusive sequences were obtained for ompA gene.

${ }^{1}$ Number of positive specimens / Total number of specimens from each flea gender; M: Male; F: Female.

infection with $R$. felis in South America has been confirmed in Brazil by molecular methods [32], and human serological evidence of $R$. felis infection has been recently reported in Colombia [33]. Moreover, there are limited reports describing Bartonella spp. in fleas from South America. A molecular study conducted in a Pulex specimen found on a Peruvian person evidenced the presence of a potential new Bartonella species [5]. Years later, our research group detected $B$. rochalimae, $B$. clarridgeiae, and $B$. henselae in P. irritans and C. felis collected from cats and dogs in Chile, suggesting the role of fleas as possible vectors of Bartonella spp. [7]

Lastly, Wolbachia spp. are alphaproteobacteria included in the family Anaplasmataceae that were first detected in fleas in 2000 [34]. In this study, the detection rate of Wolbachia spp. in P. irritans was 83\% (59/71). On the contrary, no C. felis analysed (0/8) showed evidence of carriage of Wolbachia endosymbionts. Previous studies had identified Wolbachia in around 20\% of cat fleas $[35,36]$. It has been suggested that $R$. felis infection in fleas might diminish the richness of flea microbiota [37]. According to our data, there is a strong association of
C. felis with 'Ca. R. asemboensis' whereas P. irritans is associated with Wolbachia spp. Nevertheless, the interaction of Wolbachia with R. felis or other related species, such as ' $\mathrm{Ca}$. R. asemboensis' in fleas needs further investigation.

Based on $16 \mathrm{~S}$ rDNA analysis, the presence of $Y$. pestis DNA has not been demonstrated in our fleas despite $P$. irritans having been previously described as vectors of $Y$. pestis in Ecuador [2] and plague outbreaks have been repeatedly reported in the Chimborazo region [3,4], where some flea specimens were collected. The rodent flea Xenopsilla cheopis, which is the main vector, does not exist in the inter-Andean region of Ecuador (2,500-4,000 m above sea level) possibly, due to very sudden changes in the climatic conditions [38].

\section{Conclusions}

In summary, our result confirms the presence of 'Candidatus R. asemboensis' and Wolbachia spp. in fleas removed from dogs in Ecuador. Clinicians should be aware of the potential risk of this new Candidatus Rickettsia sp. and keep in mind other flea-borne infections in areas where humans are exposed to fleas.

Table 2 Results of nucleotide sequence analysis corresponding to 59 PCR products amplified ${ }^{1}$ from the 71 Pulex irritans of this study (44 specimens from Pastaza and 27 from Chimborazo)

\begin{tabular}{lllllll}
\hline Gene & Flea gender & Location & $\begin{array}{l}\text { Length of } \\
\text { sequence (bp) }\end{array}$ & \% identity & Bacteria with closest identity in the BLAST search & Genbank \\
\hline 16S rRNA & 9/16 M; 10/28 F & Pastaza & $1287-1386$ & $98.3-100$ & Wolbachia sp. wRi endosymbiont of Drosophila simulans & NR074437 \\
& 11/13 M; 13/14 F & Chimborazo & & & & \\
& 4/16 M; 2/28 F & Pastaza & $1338-1383$ & $98.4-98.7$ & Wolbachia sp. endosymbiont of Pseudolynchia canariensis & DQ115538 \\
O/16 M; 2/28 F & Pastaza & $1300-1372$ & $98.3-99.3$ & Wolbachia sp. endosymbiont of Gryllus crickets & U83094 \\
O/16 M; 1/28 F & Pastaza & 1305 & 99.3 & Wolbachia sp. endosymbiont of Gryllus ovisopis & U83093 \\
O/16 M; 1/28 F & Pastaza & 1374 & 98.3 & Wolbachia sp. endosymbiont of Curculio hachijoensis & AB746399 \\
O/16 M; 6/28 F & Pastaza & $1291-1368$ & $98.3-99$ & Wolbachia sp. endosymbiont of Kleidocerys resedae & JQ726770 \\
\hline
\end{tabular}

${ }^{1}$ In two cases we did not obtain enough good-quality sequences to identify the bacteria, and we did not obtain amplicons for ten specimens.

${ }^{2}$ Number of positive specimens / Total number of specimens from each flea gender; M: Male; F: Female. 


\section{Competing interests}

The authors declare they have no competing interests.

\section{Authors' contribution}

Designed the study: JMV, MBL, JAO, JZC. Collected and identified fleas: JMV, $M B L, J A O, F P, J Z C$. Processed samples and analyzed sequences: AP. Analyzed the data: AP, JAO. Wrote the paper: AP, JAO. All authors read and approved the final version of the manuscript.

\section{Acknowledgments}

We are very grateful to Ana M. Palomar for her tireless help. We appreciate the support of the Red Iberoamericana para la Investigación y Control de las Enfermedades Rickettsiales, Programa Iberoamericano de Ciencia y Tecnologías para el Desarrollo (RIICER, CYTED; no. 210RT0403).

\section{Author details}

${ }^{1}$ Departamento de Enfermedades Infecciosas, Hospital San Pedro-Centro de Investigación Biomédica de La Rioja (CIBIR), C/ Piqueras 98, 26006 Logroño (La Rioja), Spain. ${ }^{2}$ Escuela Superior Politécnica de Chimborazo, Riobamba, Ecuador. ${ }^{3}$ Universidad Autónoma de Yucatán. Centro de investigaciones regionales "Dr. Hideyo Noguchi", Mérida, Yucatán, Mexico. “Laboratorio de Vectores y Enfermedades Transmitidas and Departamento de Parasitología Veterinaria, Facultad de Veterinaria, Universidad de la República, Regional Norte, Salto, Uruguay. ${ }^{5}$ Departamento de Medicina Veterinária Preventiva e Saúde Animal, Faculdade de Medicina Veterinária e Zootecnia, Universidade de São Paulo, São Paulo, Brazil.

Received: 2 May 2014 Accepted: 20 September 2014

Published online: 30 September 2014

\section{References}

1. Bitam I, Dittmar K, Parola P, Whiting M, Raoult D: Fleas and flea-borne diseases. Int J Infect Dis 2010, 14:e667-e676.

2. Ruiz A: Plague in the Americas. Emerg Infect Dis 2001, 7(Suppl. 3):539-540.

3. Gabastou JM, Proaño J, Vimos A, Jaramillo G, Hayes E, Gage K, Chu M, Guarner J, Zaki S, Bowers J, Guillemard C, Tamayo H, Ruiz A: An outbreak of plague including cases with probable pneumonic infection, Ecuador, 1998. Trans R Soc Trop Med Hyg 2000, 94:387-391.

4. Faccini-Martínez AA, Sotomayor HA: Reseña histórica de la peste en Suramérica: una enfermedad poco conocida en Colombia. Biomédica 2013, 33:8-27.

5. Parola P, Shpynov S, Montoya M, López M, Houpikian P, Zeaiter Z, Guerra H, Raoult D: First molecular evidence of new Bartonella spp. in fleas and a tick from Perú. Am J Trop Med Hyg 2002, 67:135-136.

6. Blanco JR, Pérez-Martínez L, Vallejo M, Santibáñez S, Portillo A, Oteo JA: Prevalence of Rickettsia felis-like and Bartonella spp. in Ctenocephalides felis and Ctenocephalides canis from La Rioja (Northern Spain). Ann N Y Acad Sci 2006, 1078:270-274.

7. Pérez-Martínez L, Venzal JM, González-Acuña D, Portillo A, Blanco JR, Oteo JA Bartonella rochalimae and other Bartonella spp. in fleas, Chile. Emerg Infect Dis 2009, 15:1150-1152.

8. Weisburg WG, Barns SM, Pelletier DA, Lane DJ: 16 S ribosomal DNA amplification for phylogenetic study. J Bacteriol 1991, 173:697-703.

9. Shivaji S, Bhanu NV, Aggarwal RK: Identification of Yersinia pestis as the causative organism of plague in India as determined by $16 \mathrm{~S}$ rDNA sequencing and RAPD-based genomic fingerprinting. FEMS Microbiol Lett 2000, 189:247-252.

10. Labruna MB, Whitworth T, Horta MC, Bouyer DH, McBride JW, Pinter A, Popov V, Gennari SM, Walker DH: Rickettsia species infecting Amblyomma cooperi ticks from an area in the State of Sao Paulo, Brazil, where Brazilian Spotted Fever is endemic. J Clin Microbiol 2004, 42:90-98.

11. Oliveira RP, Galvão MAM, Mafra CL, Chamone CB, Calic SB, Silva SU, Walker DH: Rickettsia felis in Ctenocephalides spp. fleas, Brazil. Emerg Infect Dis 2002, 8:317-319.

12. Fournier PE, Dumler S, Greub G, Zhang J, Wu Y, Raoult D: Gene sequencebased criteria for identification of new Rickettsia isolates and description of Rickettsia heilongjiangensis sp. nov. J Clin Microbiol 2003, 41:5456-5465.

13. Choi YJ, Lee SH, Park KH, Koh YS, Lee KH, Baik HS, Choi MS, Kim IS, Jang WJ: Evaluation of PCR-based assay for diagnosis of spotted fever group rickettsiosis in human serum samples. Clin Vaccine Immunol 2005, 12:759-763.
14. Sekeyova Z, Roux V, Raoult D: Phylogeny of Rickettsia spp. inferred by comparing sequences of 'gene $\mathrm{D}$ ', which encodes an intracytoplasmic protein. Int J Syst Evol Microbiol 2001, 51:1353-1360.

15. Jiang J, Blair PJ, Felices V, Moron C, Cespedes M, Anaya E, Schoeler GB, Sumner JW, Olson JG, Richards AL: Phylogenetic analysis of a novel molecular isolate of spotted fever group Rickettsiae from northern Peru: Candidatus Rickettsia andeanae. Ann N Y Acad Sci 2005, 1063:337-342.

16. Regnery RL, Spruill CL, Plikaytis BD: Genotypic identification of rickettsiae and estimation of intraspecies sequence divergence for portions of two rickettsial genes. J Bacterio/ 1991, 173:1576-1589.

17. Roux V, Fournier PE, Raoult D: Differentiation of spotted fever group rickettsiae by sequencing and analysis of restriction fragment length polymorphism of PCR-amplified DNA of the gene encoding the protein rOmpA. J Clin Microbiol 1996, 34:2058-2065.

18. Renesto P, Gouvernet J, Drancourt M, Roux V, Raoult D: Use of rpoB gene analysis for detection and identification of Bartonella species. J Clin Microbiol 2001, 39:430-437

19. Norman AF, Regnery R, Jameson P, Greene C, Krause DC: Differentiation of Bartonella-like isolates at the species level by PCR-restriction fragment length polymorphism in the citrate synthase gene. J Clin Microbiol 1995, 33:1797-1803.

20. Jensen WA, Fall M, Rooney J, Kordick DL, Breitschwerdt EB: Identification and differentiation of Bartonella species using a single step PCR assay. J Clin Microbiol 2000, 38:1717-1722.

21. Jiang J, Maina AN, Knobel DL, Cleaveland S, Laudisoit A, Wamburu K, Ogola E, Parola P, Breiman RF, Njenga MK, Richards AL: Molecular detection of Rickettsia felis and Candidatus Rickettsia asemboensis in fleas from human habitats, Asembo, Kenya. Vector Borne Zoonotic Dis 2013, 13:550-558

22. Jones RT, McCormick KF, Martin AP: Bacterial communities of Bartonellapositive fleas: diversity and community assembly patterns. Appl Environ Microbiology 2008, 74:1667-1670.

23. Kwong WK, Moran NA: Cultivation and characterization of the gut symbionts of honey bees and bumble bees: description of Snodgrassella alvi gen. nov., sp. nov., a member of the family Neisseriaceae of the Betaproteobacteria, and Gilliamella apicola gen. nov., sp. nov., a member of Orbaceae fam. nov., Orbales ord. nov., a sister taxon to the order 'Enterobacteriales' of the Gammaproteobacteria. Int J Syst Evol Microbiol 2013, 63:2008-2018.

24. Parola P, Sanogo OY, Lerdthusnee K, Zeaiter Z, Chauvancy G, Gonzalez JP, Miller RS, Telford SR 3rd, Wongsrichanalai C, Raoult D: Identification of Rickettsia spp. and Bartonella spp. in fleas from the Thai-Myanmar border. Ann N Y Acad Sci 2003, 990:173-181.

25. Venzal JM, Pérez-Martínez L, Félix ML, Portillo A, Blanco JR, Oteo JA: Prevalence of Rickettsia felis in Ctenocephalides felis and Ctenocephalides canis from Uruguay. Ann N Y Acad Sci 2006, 1078:305-308.

26. Labruna MB, Mattar S, Nava S, Bermudez S, Venzal JM, Dolz G, Abarca K, Romero L, de Sousa R, Oteo JA, Zavala-Castro J: Rickettsioses in Latin America, Caribbean, Spain and Portugal. Rev MVZ Córdoba 2011 , $16: 2435-2457$

27. Manock SR, Jacobsen KH, de Bravo NB, Russell KL, Negrete M, Olson JG, Sanchez JL, Blair PJ, Smalligan RD, Quist BK, Espín JF, Espinoza WR, MacCormick F, Fleming LC, Kochel T: Etiology of acute undifferentiated febrile illness in the Amazon basin of Ecuador. Am J Trop Med Hyg 2009, 81:146-151

28. Blair PJ, Jiang J, Schoeler GB, Moron C, Anaya E, Cespedes M, Cruz C, Felices V, Guevara C, Mendoza L, Villaseca P, Sumner JW, Richards AL, Olson JG: Characterization of spotted fever group rickettsiae in flea and tick specimens from northern Peru. J Clin Microbio/ 2004, 42:4961-4967.

29. Labruna MB, Ogrzewalska M, Moraes-Filho J, Lepe P, Gallegos JL, López J: Rickettsia felis in Chile. Emerg Infect Dis 2007, 13:1794-1795

30. Nava S, Pérez-Martínez L, Venzal JM, Portillo A, Santibáñez S, Oteo JA: Rickettsia felis in Ctenocephalides felis from Argentina. Vector Borne Zoonotic Dis 2008, 8:465-466.

31. Ramírez-Hernández A, Montoya V, Martínez A, Pérez JE, Mercado M, de la Ossa A, Vélez C, Estrada G, Correa MI, Duque L, Ariza JS, Henao C, Valbuena G, Hidalgo M: Molecular detection of Rickettsia felis in different flea species from Caldas, Colombia. Am J Trop Med Hyg 2013, 89:453-459.

32. Raoult D, La Scola B, Enea M, Fournier PE, Roux V, Fenollar F, Galvao MA, de Lamballerie X: A flea-associated Rickettsia pathogenic for humans. Emerg Infect Dis 2001, 7:73-81. 
33. Hidalgo M, Montoya V, Martínez A, Mercado M, De la Ossa A, Vélez C, Estrada G, Pérez JE, Faccini-Martínez AA, Labruna MB, Valbuena G: Flea-borne rickettsioses in the North of Caldas province, Colombia. Vector Borne Zoonotic Dis 2013, 13:289-294.

34. Jeyaprakash A, Hoy MA: Long PCR improves Wolbachia DNA amplification: wsp sequences found in $76 \%$ of sixty-three arthropod species. Insect Mol Biol 2000, 9:393-405.

35. Gorham CH, Fang QQ, Durden LA: Wolbachia endosymbionts in fleas (Siphonaptera). J Parasitol 2003, 89:283-289.

36. Rolain JM, Franc M, Davoust B, Raoult D: Molecular detection of Bartonella quintana, B. koehlerae, B. henselae, B. clarridgeiae, Rickettsia felis, and Wolbachia pipientis in cat fleas, France. Emerg Infect Dis 2003, 9:338-342.

37. Pornwiroon W, Kearney MT, Husseneder C, Foil LD, Macaluso KR: Comparative microbiota of Rickettsia felis-uninfected and -infected colonized cat fleas, Ctenocephalides felis. ISME J 2007, 1:394-402.

38. Sáenz Vera C: DDT in the prevention of plague in Ecuador. Bull World Health Organ 1953, 9:615-618.

doi:10.1186/s13071-014-0455-0

Cite this article as: Oteo et al.: 'Candidatus Rickettsia asemboensis' and Wolbachia spp. in Ctenocephalides felis and Pulex irritans fleas removed from dogs in Ecuador. Parasites \& Vectors 2014 7:455.

\section{Submit your next manuscript to BioMed Central and take full advantage of:}

- Convenient online submission

- Thorough peer review

- No space constraints or color figure charges

- Immediate publication on acceptance

- Inclusion in PubMed, CAS, Scopus and Google Scholar

- Research which is freely available for redistribution 